\title{
Tricuspid Annular Plane Systolic Excursion pada Bayi Kurang Bulan dan Cukup Bulan
}

\author{
Sri Endah Rahayuningsih, Herry Garna \\ Departemen Ilmu Kesehatan Anak \\ Fakultas Kedokteran Universitas Padjadjaran-Rumah Sakit Dr. Hasan Sadikin Bandung
}

\begin{abstract}
Abstrak
Bayi kurang bulan adalah bayi yang lahir dengan usia kehamilan kurang dari 37 minggu. Dibandingkan dengan bayi yang lahir normal, bayi kurang bulan memang cenderung bermasalah. Dengan prematurnya masa gestasi, maka dapat menyebabkan ketidakmatangan pada semua sistem organ, termasuk organ kardiovaskular. Tujuan penelitian ini untuk mengetahui fungsi ventrikel kanan yang diukur dengan metode tricuspid annular plane systolic excursion (TAPSE) serta fungsi ventrikel kiri dengan metode fraksi ejeksi dan fraksi pemendekan yang dilakukan dengan ekokardiografi pada bayi kurang bulan. Subjek penelitian ini bayi cukup bulan dan kurang bulan yang memenuhi kriteria inklusi, yaitu bayi sesuai masa kehamilan berusia 3-30 hari. Penelitian merupakan penelitian deskriptif analitik dengan rancangan potong lintang yang dilakukan di Departemen Ilmu Kesehatan Anak RS Dr. Hasan Sadikin Bandung, selama Juli-Oktober 2010 dengan analisis statistik menggunakan perhitungan uji t, korelasi rank Spearman. Hasil penelitian menunjukkan perbedaan antara fungsi ventrikel kanan yang diukur dengan metode TAPSE bayi kurang bulan dan bayi cukup bulan $(p=0,006)$. Tidak terdapat perbedaan yang bermakna antara fraksi ejeksi bayi kurang bulan dan cukup bulan $(\mathrm{p}=0,22)$ dan fraksi pemendekan rata-rata pada bayi kurang bulan dan bayi cukup $(p=0,20)$. Simpulan penelitian ini, ditemukan perbedaan fungsi ventrikel kanan yang diukur dengan TAPSE pada bayi kurang bulan lebih rendah dibandingkan dengan bayi cukup bulan. [MKB. 2011;43(4):178-82].
\end{abstract}

Kata kunci: Bayi cukup bulan, bayi kurang bulan, ekokardiografi, fungsi ventrikel kanan, TAPSE

\section{TricuspidAnnular Plane Systolic Excursion in Preterm and Term Babies}

\begin{abstract}
A preterm infant is a baby born with gestational age less than 37 weeks. Preterm babies tend to have problems compared to normal ones. Premature gestational age might result in immaturity of all organ systems of the body including cardiovascular organs. The aim of this study was to find out the right ventricle function by tricuspid annular plane systolic excursion (TAPSE) and left ventricle by ejection fraction and shortening fraction using echocardiography on preterm babies. The subject of this study were term and preterm babies who fulfilled the inclusion criteria: appropiate gestational age babies 3-30 days old. This was an analytic descriptive study with cross-sectional method held in Department of Child Health Dr. Hasan Sadikin Hospital Bandung during JulyOctober 2010, and statistical analysis using t-test Spearman rank correlation test. The result of the study showed that the right ventricle function examined by TAPSE method was different on preterm compared to term babies $(p=0.006)$. No significant difference was found in the ejection fraction between preterm and term babies $(p=0.22)$ and so did the shortening fraction $(\mathrm{p}=0.20)$. It was concluded that there is a difference in the right ventricle function by TAPSE method between preterm (lower) and term babies. [MKB. 2011;43(4):178-82].
\end{abstract}

Key words: Echocardiography, preterm baby, right ventricle function, TAPSE, term baby

\footnotetext{
Korespondensi: Dr. Sri Endah Rahayuningsih, dr., SpA(K), Departemen Ilmu Kesehatan Anak Fakultas Kedokteran Universitas Padjadjaran-Rumah Sakit Dr. Hasan Sadikin, jalan Pasteur 38 Bandung 40161, telepon/faks (022) 2034426, e-mail: endah.perkani@gmail.com
} 


\section{Pendahuluan}

Bayi kurang bulan adalah bayi yang lahir dengan usia kehamilan kurang dari 37 minggu. Dibandingkan dengan bayi yang lahir normal, bayi kurang bulan memang cenderung bermasalah. Dengan prematurnya masa gestasi, maka dapat menyebabkan ketidakmatangan pada semua sistem organ, termasuk organ kardiovaskular. ${ }^{1-3}$ Selain belum matang, pada periode neonatal dini terjadi beberapa perubahan kardiovaskular yang melibatkan adaptasi miokardium seperti penurunan tahanan vaskular paru dan peningkatan aliran darah paru, peningkatan tahanan vaskular sistemik, penutupan duktus arteriosus, penutupan foramen ovale, dan penutupan duktus venosus. Volume ventrikel kanan janin lebih besar dibandingkan dengan volume ventrikel kiri, tetapi setelah lahir volumenya menjadi sama. Pada masa transisi ini, ventrikel kanan yang dominan kemudian secara perlahan akan diambil alih oleh ventrikel kiri, sehingga ventrikel kanan menjadi sangat penting peranannya. ${ }^{4}$

Ventrikel kanan mempunyai ciri-ciri khusus. Letak ruang ventrikel kanan paling depan di dalam rongga dada, yaitu tepat di bawah manubrium sterni. Sebagian besar ventrikel kanan berada di kanan depan ventrikel kiri dan medial atrium kiri, berbentuk bulan sabit/setengah bulatan berdinding tipis dengan tebal 4-5 mm yang disebabkan oleh tekanan di ventrikel kiri yang lebih besar. Dinding anterior dan inferior disusun oleh serabut otot, yaitu trabekula karnae yang sering membentuk persilangan satu sama lain. Otot ini di bagian apikal berukuran besar, yaitu trabekula septo marginal (moderator band). ${ }^{5,6}$ Karena bentuknya yang unik ini, maka terdapat kesulitan untuk mengukur fungsi ventrikel kanan. Tricuspid annular plane systolic excursion (TAPSE) merupakan salah satu cara pengukuran fungsi ventrikel kanan dengan menggunakan ekokardiografi.?

Tujuan penelitian ini untuk mengetahui fungsi ventrikel kanan yang diukur dengan metode TAPSE dan fungsi ventrikel kiri dengan metode fraksi ejeksi dan fraksi pemendekan yang dilakukan dengan ekokardiografi pada bayi kurang bulan.

\section{Metode}

Penelitian potong lintang dilakukan pada bulan Juli-Oktober 2010. Subjek dipilih secara konsekutif dari bayi cukup bulan dan kurang bulan yang lahir dan dirawat di ruang Perinatologi RS Dr. Hasan Sadikin Bandung setelah mendapat persetujuan (informed consent) dari orangtua. Kriteria inklusi bayi cukup bulan dan bayi kurang bulan sehat, sesuai masa kehamilan, berusia 3-30 hari, sedangkan kriteria eksklusi bayi yang memiliki penyakit jantung bawaan, kelainan pada paru, congenital multiple anomaly, lahir dengan asfiksia, dan mempunyai kelainan sistemik. Dengan batas kemaknaan $5 \%$ dan power test $80 \%$ didapatkan besar sampel 16 untuk masing-masing kelompok sehingga jumlah sampel minimal sebanyak 32 . Pada subjek dilakukan pemeriksaan fisis dan ekokardiografi untuk mengukur pemeriksaan fungsi ventrikel kanan dengan metode TAPSE serta fungsi ventrikel kiri dengan metode fraksi ejeksi dan fraksi pemendekan. Ekokardiografi dilakukan di Instalasi Pelayanan Jantung oleh seorang konsultan pediatrik kardiologi dengan bayi tidur terlentang dan terpasang elektrokardiografi (EKG). Pengukuran TAPSE dilakukan pada pandangan apikal 4 ruang. Dengan menggunakan M-mode, kursor diletakkan di anulus trikuspid sejajar dengan gerakan anulus tersebut, kemudian diukur jarak (distance) titik anulus trikuspid pada sistolik dan diastolik. ${ }^{6,7}$

Pemeriksaan fraksi ejeksi ventrikel kiri dengan ekokardiografi M-mode pada potongan sumbu panjang parasternal, kursor diletakkan pada ujung katup mitral dengan monitor EKG. ${ }^{6,7}$ Fraksi ejeksi

$(\mathrm{FE})=\underline{\mathrm{DVKI}-\mathrm{AD}-\mathrm{DVKI}-\mathrm{AS} \times 100 \%}$ DVKI-AD

Keterangan:

DVKI-AD: dimensi ventrikel kiri pada saat akhir diastol

DVKI-AS: dimensi ventrikel kiri pada saat sistol

Untuk mengetahui perbedaan TAPSE, fraksi ejeksi dan fraksi pemendekan antara bayi kurang bulan dan cukup bulan dipakai uji analisis t. Selanjutnya untuk menilai kolerasi antara TAPSE ventrikel kanan dan usia kehamilan dipakai uji korelasi rank Spearman, dengan kemaknaan $\mathrm{p}<0,05$.

\section{Hasil}

Dari 41 subjek penelitian yang dilakukan pemeriksaan ekokardiografi ditemukan dua bayi pada kelompok bayi cukup bulan dengan kelainan jantung bawaan, yaitu defek setum atrium (5\%) dan persistent ductus arteriosus (PDA) 2 $\mathrm{mm}$ disertai dengan persistent forament ovale $(5 \%)$, sedangkan pada kelompok bayi kurang bulan ditemukan satu bayi dengan defek septum ventrikel tipe muskular $(2 \%)$, walaupun pada pemeriksaan fisis tidak ditemukan kelainan. Bayi yang mengalami penyakit jantung bawaan (PJB) tersebut dikeluarkan dari penelitian, sehingga jumlah subjek pada saat analisis data sebanyak 19 bayi kurang bulan dan 19 bayi cukup bulan. Karakteristik umum subjek penelitian meliputi 


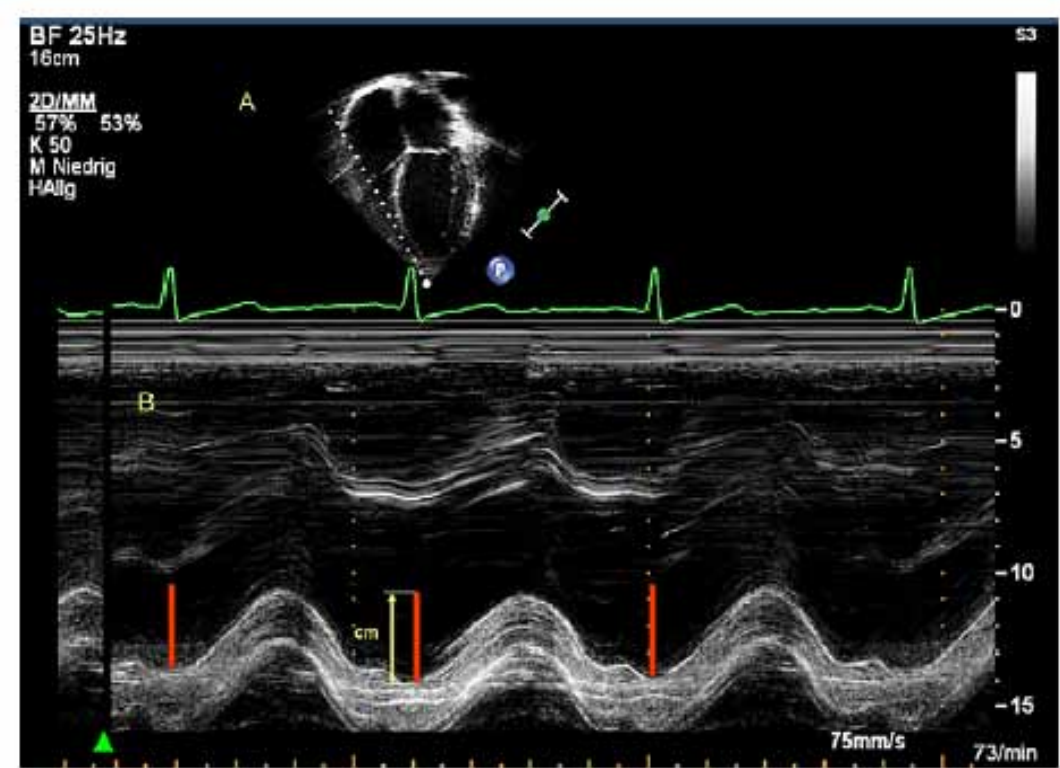

Gambar Apikal 4-chamber View. (A) Garis Putih Terputus-putus Menunjukkan Kursor M-mode yang Diletakkan pada Anulus Lateral Katup Trikuspid. (B) Gambaran M-mode dari TAPSE pada Penderita dengan Fungsi RV dan LV Normal

Hasil pengukuran pergerakan longitudinal (sentimeter) ditunjukkan oleh garis merah. Panah kuning menandai batas pengukuran atas dan bawah

Tabel 1 Karakteristik Umum Subjek Penelitian

\begin{tabular}{ccc}
\hline Karakteristik & Bayi Kurang Bulan $(\mathbf{n}=\mathbf{1 9})$ & Bayi Cukup Bulan $(\mathbf{n}=\mathbf{1 9})$ \\
\hline Jenis kelamin & & \\
Laki-laki & 10 & 6 \\
Perempuan & 9 & 6 \\
Usia kehamilan (minggu) & 32,32 & 38,57 \\
$\quad$ Rata-rata & 2,87 & 0,50 \\
Simpang Baku & & \\
Berat badan & $1.576,31$ & $3.013,15$ \\
Rata-rata & 156,67 & 281,78 \\
Simpang baku & &
\end{tabular}

jenis kelamin, usia kehamilan, dan berat badan (Tabel 1).

Untuk menentukan korelasi antara nilai TAPSE dan usia kehamilan, digunakan uji korelasi rank Spearman (Tabel 3). Terdapat korelasi yang bermakna antara TAPSE dan usia kehamilan $(\mathrm{p}=0,000)$.

\section{Pembahasan}

Penilaian fungsi sistolik ventrikel kanan masih merupakan tantangan karena sering kali secara teknis sulit melakukannya terutama penilaian fungsi ventrikel kanan yang berdasarkan model geometri. Kesulitan ini terjadi karena beberapa

Tabel 2 Perbedaan TAPSE Bayi Kurang Bulan dan Bayi Cukup Bulan

\begin{tabular}{cccc}
\hline Variabel & $\begin{array}{c}\text { Bayi Kurang Bulan } \\
\text { Rata-rata(SB) }\end{array}$ & $\begin{array}{c}\text { Bayi Cukup Bulan } \\
\text { Rata-rata(SB) }\end{array}$ & p \\
\hline Fraksi ejeksi $(\%)$ & $64,21(2,09)$ & $65,78(2,17)$ & 0,22 \\
Fraksi pemendekan & $35,73(1,24)$ & $35,57(0,507)$ & 0,20 \\
TAPSE & $15,26(2,62)$ & $22,84(1,34)$ & 0,006 \\
\hline
\end{tabular}


Tabel 3 Korelasi antara TAPSE dan Usia Kehamilan

\begin{tabular}{lcc}
\hline Korelasi antara TAPSE dan Usia Kehamilan & $\mathbf{r}_{\mathbf{s}}$ & $\mathbf{p}$ \\
\hline TAPSE $(\mathrm{cm})$ & 0,743 & 0,000 \\
Fungsi ventrikel kiri & & \\
Fraksi ejeksi & 0,317 & 0,052 \\
Fraksi pemendekan & 0,059 & 0,723 \\
\hline
\end{tabular}

hal, yaitu posisinya yang anterior retrosternal, batas endokardium ventrikel kanan yang tidak jelas karena mempunyai trabekula yang kasar, struktur ventrikel kanan tidak dapat dilihat secara keseluruhan dalam satu bidang pemeriksaan, serta dipengaruhi oleh preload, afterload, dan fungsi ventrikel kiri. Selain itu, struktur ventrikel kanan secara anatomi dan fungsinya terbagi menjadi dua bagian, inflow dan outflow track yang dipisahkan oleh berkas otot tebal dalam ruang ventikel kanan. Masalah yang paling utama dalam penilaian fungsi sistolik ventrikel kanan, yaitu geometrinya sangat kompleks dengan bentuk iregular, asimetris, crescentric, dan truncated. Pendekatan yang lebih sederhana untuk memperkirakan fungsi ventrikel kanan dengan mengukur TAPSE. Tricuspid annular plane systolic excursion merupakan teknik lain untuk memeriksa fungsi sistol ventrikel kanan yang memiliki korelasi baik terhadap fraksi ejeksi berdasarkan angiografi radionuklida, MRI, dan ekokardiografi 2 dimensi pada dewasa. Metode ini mengukur pemendekan ventrikel kanan pada sumbu longitudinal. ${ }^{7,8}$ Koestenberger $\mathrm{dkk} .{ }^{8}$ meneliti fungsi ventrikel kanan menggunakan TAPSE pada 640 bayi, anak, dan remaja sehat. Nilai TAPSE rata-rata pada bayi usia $0-30$ hari sebesar 0,91 (SD 0,68-1,15). Dari penelitian tersebut didapatkan hasil bahwa nilai TAPSE meningkat secara nonlinear dengan bertambahnya usia. Tidak ada perbedaan yang bermakna nilai TAPSE antara laki-laki dan perempuan. Nilai TAPSE berkorelasi terhadap usia neonatus dan bayi mempunyai nilai TAPSE yang lebih rendah dibandingkan dengan anak yang lebih besar atau remaja, meskipun fungsi sistol ventrikel kanan normal. Masih belum jelas apakah rendahnya TAPSE pada bayi disebabkan oleh perubahan yang berhubungan dengan pertumbuhan pada populasi anak atau menunjukkan perubahan fungsi sistol pada bayi karena kondisi ventrikel yang belum matang. ${ }^{7-9}$

Pada penelitian ini terdapat perbedaan TAPSE antara bayi kurang bulan dan bayi cukup bulan, karena pada saat sistol, terjadi kontraksi miokardium ke arah longitudinal, radial, dan sirkumferensial. Pada ventrikel kanan, gerakan longitudinal merupakan gerak yang dominan pada fase sistol. Gerakan memendek pada sistol dan kembali memanjang ke posisi semula dapat dilihat dari gerakan anulus trikuspid. Jarak pergerakan anulus tersebut dapat menggambarkan fungsi kontraksi ventrikel kanan..$^{7-9}$ Gerakan ini tidak sama pada bayi kurang bulan maupun bayi cukup bulan, karena terdapat perbedaan maturasi miokardium, sehingga terdapat perbedaan TAPSE antara bayi kurang bulan dan bayi cukup bulan.

Fraksi ejeksi rata-rata pada bayi kurang bulan 64,21 (SB 2,09)\%, sedangkan pada bayi cukup bulan 65,78 (SB 2,17)\%. Berdasarkan uji t berpasangan ternyata tidak terdapat perbedaan bermakna antara fraksi ejeksi bayi kurang bulan dan cukup bulan $(p=0,22)$ (Tabel 2). Fraksi pemendekan rata-rata pada bayi kurang bulan $35,73(\mathrm{SB}=1,24)$, sedangkan pada bayi cukup bulan $35,57(\mathrm{SB}=0,507)$. Hasil uji t berpasangan tidak terdapat perbedaan bermakna fraksi pemendekan antara bayi kurang bulan dan bayi cukup bulan $(\mathrm{p}=0,20)$. Hasil ini berbeda dengan penelitian sebelumnya yang menyatakan fraksi pemendekan bayi kurang bulan lebih rendah dibandingkan dengan bayi cukup bulan yang disebabkan pendataran septum interventrikular ke dalam ventrikel kiri dan berkurangnya gerakan segmen ini berkaitan dengan rendahnya pengukuran fraksi pemendekan. Hal ini mungkin disebabkan oleh tahanan vaskular paru dan perbedaan tekanan transeptal antara ventrikel kiri dan kanan. ${ }^{10}$

Dengan hasil tersebut dapat dikatakan bahwa faal sistol ventrikel kiri bayi kurang bulan lebih rendah dan berbeda bermakna dengan bayi cukup bulan, walaupun sebenarnya keduanya masih dalam rentang normal. Hasil penelitian ini sesuai dengan penelitian sebelumnya yang menunjukkan pada bayi kurang bulan terdapat perbedaan dalam ukuran dan gerakan dinding ventrikel kiri. Perbedaan ini ditandai oleh pendataran septum interventrikular ke dalam ventrikel kiri dan berkurangnya gerakan segmen ini berkaitan dengan rendahnya pengukuran fraksi pemendekan. Hal ini mungkin disebabkan oleh tahanan vaskular paru dan perbedaan tekanan transeptal antara ventrikel kiri dan miokardium yang imatur, ${ }^{10}$ yaitu perbandingan jumlah kolagen miokardium tipe I yang kaku pada bayi kurang bulan lebih banyak dibandingkan dengan kolagen miokardium tipe III yang lebih elastik. Pada 
penelitian ini fungsi ventrikel kiri tidak berbeda antara bayi kurang bulan dan bayi cukup bulan, karena pada bayi baru lahir, bayi cukup bulan, dan bayi kurang bulan mempunyai fungsi ventrikel kiri yang sama. Pada bayi cukup bulan maupun kurang bulan, ventrikel kanan akan bekerja lebih dominan dibandingkan dengan ventrikel kiri.

Simpulan, terdapat perbedaan fungsi ventrikel kanan yang diukur dengan TAPSE, pada bayi kurang bulan lebih rendah dibandingkan dengan bayi cukup bulan. Diperlukan kehati-hatian dalam menangani bayi kurang bulan mengingat tahanan vaskular paru yang masih tinggi menyebabkan dilatasi ventrikel kanan dan akan berdampak pada fungsi ventrikel kanan.

\section{Daftar Pustaka}

1. Praveen K, Suresh G. Complication after preterm birth: an overview for emergency physicians. Clin Ped Emerg Med. 2008; 9:191-9.

2. Holland MG, Refuerzo JS, Ramin SM, Saade GR, Blackwell SC. Late preterm birth: how often is it avoidable. Am J Obstet Gynecol. 2009;201:404eI-4.

3. Ramachandrappa A. Health issues of late preterm infant. Pediatr Clin $\mathrm{N}$ Am. 2009;56:565-77.

4. Park MK. Pediatric cardiology for practitioners. Edisi ke-5. Philadelphia: Mosby; 2008.

5. Driscoll DJ. Fundamentals of pediatric cardiology. Edisi ke-1. Baltimore: Lippincott
Williams \& Wilkins; 2006.

6. Mertens LL, Rigby ML, Horowitz ES, Anderson RH. Cross sectional echocardiographic and Doppler imaging. Dalam: Anderson RH, Baker EJ, Penny D, Redington AN, Rigby ML, Wernovsky G, penyunting. Pediatric cardiology. Edisi ke-3. Philadelphia: Churchill Livingstone; 2010. hlm. 1020-5.

7. Lai WW, Geva T, Shirali GS, Frommelt PC, Humes RA, Brook MM, dkk. Guidelines and standards for performance of a pediatric echocardiogram: a report from the Task Force of the Pediatric Council of the American Society of Echocardiography. J Am Soc Echocardiogr. 2006;19(12):1413-30.

8. Koestenberger $M$, Ravekes W, Everett $\mathrm{AD}$, Stueger HP, Heinzl B, Gamillscheg A, dkk. Right ventricular function in infants, children and adolescents: reference values of the tricuspid annular plane systolic excursion (TAPSE) in 640 healthy patients and calculation of $\mathrm{z}$ score values. J Am Soc Echocardiogr. 2009;22(6):715-9.

9. Miller D, Farah MG, Liner A, Fox K, Schluchter M, Hoit BD. The relation between quantitative right ventricular ejection fraction and indices of tricuspid annular motion and myocardial performance. J Am Soc Echocardiogr. 2004;17(5):443-7.

10. Barlow AJ, Ward C, Webber SA, Sinclair BG, Potts JE, Sandor GG. Myocardial contractility in premature neonates with and without patent ductus arteriosus. Pediatr Cardiol. 2004;25(2):102-7. 